ORIGINAL RESEARCH PAPER

\section{A COIMPARATIVE STUDY OF PERCUTANEOUS NEEDLE ASPIRATION AND CATHETER DRAINAGE IN MANAGEMENT OF LIVER ABCESS}

General Surgery

KEY WORDS:
Dr. Haresh G. Memariya*

Dr. Rajnish R. Patel

Dr. Hitendra $\mathbf{K}$. Desai

Dr. Rajesh K. Patel

Dr. Deep N. Patel

Dr. Anand M

Dr. T Srinivas

Dr. Darshan

Gohel

Dr. Shivangi

Dangi
Second Year Resident Doctor, Department of General Surgery, B.J.M.C and Civil Hospital, Ahmedabad . *Corresponding Author

Professor \& Head of unit, Department of General Surgery, B.J.M.C and Civil Hospital, Ahmedabad.

Assistant Professor, Department of General Surgery, B.J.M.C and Civil Hospital, Ahmedabad.

Assistant Professor, Department of General Surgery, B.J.M.C and Civil Hospital, Ahmedabad.

Second Year Resident Doctor, Department of General Surgery, B.J.M.C and Civil Hospital, Ahmedabad.

Second Year Resident Doctor, Department of General Surgery, B.J.M.C and Civil Hospital, Ahmedabad.

Second Year Resident Doctor, Department of General Surgery, B.J.M.C and Civil Hospital, Ahmedabad.

First Year Resident Doctor, Department of General Surgery, B.J.M.C and Civil Hospital, Ahmedabad.

$2^{\text {nd }}$ Year Resident Doctor, Department of General Surgery, B.J.M.C and Civil Hospital, Ahmedabad.

Modern management of liver abcess include a combination of percutaneous Needle aspiration or percutaneous Catherter drainage along with intravenous antibiotic .Liver abcess is common disease in india, if not treated properly can lead to hazardous complication.

MATERIAL AND METHOD: This was comparative study of 30 patient from august 2018 to August2020 in civil hospital ahmedabad. Randomization was done and dived into two groups of 25 each and assigned two group as percutaneous Catherter drainage and needle aspiration. Both groups were given intravenous antibiotics for 7 days .Both modalities were performed under guidance of ultrasound imaging. Needle aspiration was repeated for three times and if size of abcess cavity not reduced to half consider as failure of treatment. Effectiveness of treatment measured in term of days to achieve clinical improvement, total/near total resolution of abcess cavity and duration of hospital stay.

RESULT: Needle aspiration was successful in 13 out of 15, whereas percutaneous drainage was successful in 14 out of 15.Duration of hospital stay were significantly lower in percutaneous drainage.one patient with needle aspiration developed subcapsular hematoma.

CONCLUSION: We can conclude that percutaneous drainage is better modality is better modality as compared to needle aspiration in medium to large size liver abcess. The duration of hospital stay is comparatively lower in percutaneous drainage and days of clinical relief were earlier in percutaneous drainage. This study also verify that both were adequately effective in the treatment of liver abcess.

Aim Of The Study: To compare the effectiveness of percutaneous catheter drainage and percutaneous needle aspiration in management of liver abcess.

\section{INTRODUCTION}

Liver abscess is an intra abdominal or visceral abscess, a cavity containing pus present in the liver. With the advent of newer imaging techniques and availability of broadspectrum antibiotics, the management of liver abscess is now imaging based percutaneous needle aspiration or catheter drainage. Some consider percutaneous catheter drainage along with intravenous broad-spectrum antibiotics as a readily accepted and safe effective treatment of a liver abscess. Some consider needle aspiration as better procedure as it is less aggressive, risky and complicated, but this requires follow-up repeated monitoring by investigations.

\section{METHOD AND MATERIAL}

The study was carried out on 50 patients who were having liver abscess of $5 \mathrm{~cm}$ in any diameter by ultrasonography after taking a detailed history and general examination. The study www.worldwidejournals.com | conducted from August 2019 to August 2020 in Civil Hospital Ahmedabad.

Patients were randomized into two group-

1)25 patients in Group $A$ (catheter drainage)

2)25 patients in Group B (needle aspiration)

A disposable trocar needle of $16 \mathrm{G}$ will be inserted, and the abscess from the cavity is aspirated and it is repeated if there is no reduction in the size of abscess cavity or no clinical improvement in clinical features. Aspiration is done maximum up to three times.

For catheter insertion, a pigtail catheter of 12- 20F with a guiding stilett will be inserted. The whole of the abscess cavity was evacuated by manual syringe suction, then the catheter will be sutured to the skin and connected to the collection bag. 
From this day USG is being done every third day till abscess cavity is fully evacuated and removed if the collection was nil for the last 24 hours.

Table 1-Distribustion Of Patients Based On Gender.

\begin{tabular}{|l|l|l|}
\hline & CATHETER DRAINAGE & NEEDLE ASPIRATION \\
\hline FEMALE & $5(20 \%)$ & $6(24 \%)$ \\
\hline MALE & $20(80 \%)$ & $19(76 \%)$ \\
\hline
\end{tabular}

Table 2- Average Days Of Hospital Stays And I.V. Antibiotic

\begin{tabular}{|l|l|l|}
\hline & $\begin{array}{l}\text { Avg day of } \\
\text { hospital stay }\end{array}$ & $\begin{array}{l}\text { Average day of iv } \\
\text { antibiotic }\end{array}$ \\
\hline Catheteer Drainage & 9 & 8 \\
\hline Needle Aspiration & 11 & 9.5 \\
\hline
\end{tabular}

Table 3- Assosiation Between Different Groups And Outcome

\begin{tabular}{|l|l|l|l|l|}
\hline & & $\begin{array}{l}\text { Catheter } \\
\text { Drainage }\end{array}$ & $\begin{array}{l}\text { Needle } \\
\text { Aspiration }\end{array}$ & Total \\
\hline FAILURE & COUNT & 1 & 4 & 5 \\
\hline & & $2 \%$ & $8 \%$ & $10 \%$ \\
\hline SUCCESS & COUNT & 24 & 21 & 45 \\
\hline & & $98 \%$ & $92 \%$ & $90 \%$ \\
\hline
\end{tabular}

Table 4 - Association Between Different Groups And Reoccurance After 1 Month

\begin{tabular}{|l|l|l|l|l|}
\hline $\begin{array}{l}\text { Reoccurance } \\
\text { After 1 Month }\end{array}$ & & $\begin{array}{l}\text { Catheter } \\
\text { Drainage }\end{array}$ & $\begin{array}{l}\text { Needle } \\
\text { Aspiration }\end{array}$ & Total \\
\hline NO & COUNT & 23 & 20 & 43 \\
\hline & & $92 \%$ & $80 \%$ & $86 \%$ \\
\hline YES & COUNT & 2 & 5 & 7 \\
\hline & & $08 \%$ & $20 \%$ & $14 \%$ \\
\hline
\end{tabular}

Table 5- Association Between Different Groups And Reoccurance After 3 Months

\begin{tabular}{|l|l|l|l|l|}
\hline $\begin{array}{l}\text { Reoccurance } \\
\text { After 3 Months }\end{array}$ & & $\begin{array}{l}\text { Catheter } \\
\text { Drainage }\end{array}$ & $\begin{array}{l}\text { Needle } \\
\text { Aspiration }\end{array}$ & Total \\
\hline NO & COUNT & 24 & 23 & 47 \\
\hline & & $96 \%$ & $92 \%$ & $94 \%$ \\
\hline YES & COUNT & 1 & 2 & 3 \\
\hline & & $4 \%$ & $8 \%$ & $6 \%$ \\
\hline
\end{tabular}

Table 6- Association Between Different Groups And Reoccurance After 6 Months

\begin{tabular}{|l|l|l|l|l|}
\hline $\begin{array}{l}\text { Reoccurance } \\
\text { After 6 Months }\end{array}$ & & $\begin{array}{l}\text { Catheter } \\
\text { Drainage }\end{array}$ & $\begin{array}{l}\text { Needle } \\
\text { Aspiration }\end{array}$ & Total \\
\hline NO & COUNT & 23 & 23 & 23 \\
\hline & & $92 \%$ & $92 \%$ & $92 \%$ \\
\hline YES & COUNT & 2 & 2 & 4 \\
\hline & & $8 \%$ & $8 \%$ & $8 \%$ \\
\hline
\end{tabular}

Table 7-Complication

\begin{tabular}{|l|l|l|}
\hline & Catheter Drainage & Needle Aspiration \\
\hline Complication & 3 & 4 \\
\hline$\%$ & $12 \%$ & $16 \%$ \\
\hline No Complication & 22 & 21 \\
\hline$\%$ & $88 \%$ & $84 \%$ \\
\hline
\end{tabular}

\section{DISCUSSION}

- A 50 patients of liver abscess were randomly distributed into catheter drainage and needle aspiration groups. It was found that 30 (60\% of total) cases belonged to amoebic liver abscess while 20 (40\% of total) cases belonged to pyogenic category.

- Total average duration of intravenous antibiotic administration needed for patients in the catheter drainage group was 8 days ; for needle aspiration group were 9.5.

- The average duration of hospital stay for patients in the catheter drainage group was 9 days; for needle aspiration group were 11.

- Regarding clinical efficacy of the two percutaneous methods, it was found that both Of them were effective against treatment of liver abscess which was recorded in terms of post intervention improvement in various clinical parameters as relieve in pain, jaundice, fever, decreases in hepatomegaly.

- Out of 25 patients in the catheter drainage group, 2 (8\%) patient showed recurrence after 1 month. Out of 25 patients in the needle aspiration group, 5 (20\%) patient showed recurrence after 1 month.

- The success rate in catheter drainage group was $92 \%$ and that in needle aspiration group was $80 \%$.

- Complication related to needle aspiration was haemorrhage in four cases which stopped spontaneously without hemodynamic compromise. Complication related to catheter drainage group was bile leak in three cases which stopped spontaneously.

\section{CONCLUSION}

From our prospective study, we can conclude that the percutaneous continuous catheter drainage is better modality as compared to percutaneous intermittent needle aspiration in medium to large size liver abscess in several aspects.

The duration of hospital stay is comparatively lower in percutaneous catheter drainage and days of clinical relief were earlier in percutaneous catheter drainage.

This study also verifies that both the percutaneous modalities were adequately effective in the treatment of liver abscess in terms of improvement in clinical features and laboratory investigations.

Our study also verifies that the recurrence rate is considerably higher in percutaneous needle aspiration.

Regarding clinical efficacy of the two percutaneous methods, it was found that both of them were effective against treatment of liver abscess which was recorded in terms of post intervention improvement in various clinical parameters as relieve in pain, jaundice, fever, decreases in hepatomegaly.

\section{REFERENCES}

1. Bailey and Love: Short practice of surgery 27th edithion.

2. Farquharson's Textbook of surgery: 10th edition.

3. Schwartz-Principle of surgery 9th edition.

4. Hamilton and Bailey-Physical sign in clinical surgery-13th edition.

5. Sabiston Textbook of Surgery-First South Asia Edition

6. Sharma MP , Rai RR, Acharya SK. Needle Aspiration of amoebic liver abcess.BMJ.1989;299

7. Tandon A, Jain AK, Kixit VK, Agrawal AK, Gupta JP. Needle Aspiration in large amoebic liver abcess. 1997;18(1):19-21.

8. Freeman O, Akamaguna A, Jarike LN. Amoebic liver abcess: The effect of aspiration on the resolution or healing time. Ann Trop Med Parisitol.

9. Ramani A, Ramani R, Kumar MS, Lakhkar BN, Kundaje GN. Ultrasound guided needle aspiration of amoebic liver abscess. Postgrad Med J. 1993;69(811):381-3. 17. Enver Zerem, Amir Hadzic. Sonographically guided Percutaneous Catheter Drainage Versus Needle Aspiration in the management of Pyogenic Liver Abscess. AJR 2007;189: 138-142.

10. Pitt HA . Surgical management of hepatic liver abscess, World J Surg. 1990;14(4):498-504.

11. Rintoul R, O'Riordain MG, Laurenson IF, Crosbie JL, Allan PL, Garden OJ. Changing management of pyogenic liver abscess.Br J Surg. 1996;83:1215-1218.

12. McFadzean AJS, Chang KPS, Wong CC.Solitary pyogenic liver abscess of the liver treated by closed aspiration and antibiotics: A report of 14 consecutive cases with recovery. Br J Surg. 1953;41:141-152.

13. Barakate MS, Stephen MS, Waugh RC, Gallagher PJ, Solomon MJ, Storey DW, Sheldon DM. Pyogenic liver abscess: A review of 10 years's experience in management. Aust N Z J Surg. 1999;69:205-209.

14. Medical Record Office, Civil hospital , B J Medical college, Ahmedabad2018-2020 